\title{
The Land of the Dragon and the Pharaohs: Egypt and China in the New Millennium
}

\author{
Mohamed Abd El-Sattar Elbadri
}

Separated by thousands of miles, a sea and two oceans, yet linked by civilization, history and the realities of world politics, both Egypt and China have embarked on a new trajectory of mutual cooperation as never before. This relationship has become a geostrategic, economic and political imperative rather than a luxury, which transcends ideology and distance. The two states have undergone major developments that have propelled them into the future. China has hyper-jumped into the international stage as a world power without having to go through traditional axioms of shifts in international power distribution and global turbulence, while Egypt underwent two revolutions culminating in a new trajectory of socio-economic and political development that is reestablishing its leadership role in the region and impelling it to resume playing a strong role as a regional and stable power in a rather turbulent region.

If we adopt Napoleon's maxim that "the policies of states are inherent in their geography," we can confidently claim that both China and Egypt, using Mackinder's phrase, are "geographic pivots"; the first on the world stage, and the second in its own region with geopolitical implications internationally. It is quite normal that geopolitical pivots interact and foster relationships conducive to their interests. This is further strengthened by many factors which include inter-alia:

- Firstly, the adoption of Egypt's doctrine of diversification of its foreign policy. This opened the road for it to strengthen its strategic relationship with all states equally without prejudice, thereby paving the road to further outreach globally, especially with major powers.

- Second, the joint belief of both Cairo and Beijing, that such relations are to be conducted within a framework of mutual interest, respect of international law, and further strengthened by common visions regarding many of the issues of both world and regional politics.

M. A. E.-S. Elbadri ( $ه)$

Embassy of the Arab Republic of Egypt to the People's Republic of China, Beijing, China

(C) The Author(s) 2022

H. Wang and L. Miao (eds.), China and the World in a Changing Context,

China and Globalization, https://doi.org/10.1007/978-981-16-8086-1_18 
- Third, being geopolitical pivots has opened ways for cooperation, especially with the launching of Beijing's Belt and Road Initiative, to which Egyptian President Abdelfattah El-Sisi has committed in terms of nearly all of its international frameworks. Egypt is an important anchor for this initiative, owing to the presence of the Suez Canal as well as other geopolitical considerations.

- Fourth, the firm belief of China's value-added role in Egypt's development has made it a very valuable partner based on a win-win scenario.

All these factors have contributed to put the Egyptian-Sino relationship on track with a mutual conviction to make it successful.

Egypt has played the role of an integral regional player throughout different eras and at historic turning points. It is a country situated in a strategic location at a vital crossroads between Africa, Asia and Europe, which has made it of special significance to the world as a hub for trade between the East and West for centuries. Being the heart of the political, cultural and economic life of the Middle East and North Africa throughout its millennia-long civilization most certainly did not escape the eyes of Chinese policy makers.

Likewise China, throughout its thousands of years of continuous history and as one of the world's most ancient civilizations, has played a crucial role in Asia and today in the world. Furthermore, its meteoric rise over the past four decades has made it the world's second largest economy and a crucial player on the regional and global scene, with an important presence in the international scene. This was internationally recognized worldwide and in Egypt as well. The potential of such a strategic partnership was ready to be tapped by both capitals for the best interest of both countries.

Fortunately, this new partnership did not have to begin from scratch and already had a solid base. This year marks the 65th anniversary of the establishment of diplomatic relations between Egypt and China. Egypt was the first Arab and African country to establish diplomatic ties with the People's Republic of China, and since then Egypt and China have maintained profound, strategic and solid relations. Both countries played a crucial role in the establishment of the Non-Alignment Movement, which also sees its 60-year anniversary this year, and have championed the causes of developing countries and regions to this day. They have also defended their right to achieve their own models of governance and development. Furthermore, they promoted and led South-South cooperation to realize the aspirations of their own peoples for just and equitable development. Together, both have advanced the interests of developing countries through their strong upholding of a multilateral rules-based system.

The current surge in the relationship between both parties intensified under the leadership of H.E. Abdelfattah El-Sisi, President of the Arab Republic of Egypt and H.E. President Xi Jinping, President of the People's Republic of China, elevating the relationship to the level of a "Comprehensive Strategic Partnership" in of 2014, which marked the democratic accession of President El-Sisi to the presidency. Additionally, both countries share common values and principles pertaining to stability, peace and combating terrorism, making it even more natural that such a strong strategic 
relationship between both countries would come to fruition. A further decision by Beijing and Cairo to elevate the status of relations was made during the last visit of State Councilor and Minister of Foreign Affairs Wang Yi to Cairo in January 2020; both parties are developing the framework for this new strategic partnership.

Economic and trade relations between Egypt and China are a strong reflection of the indispensable ties between both countries. China is Egypt's largest trading partner, with bilateral trade reaching USD 14.5 billion despite the negative impact of the COVID-19 pandemic on the global economy. And, as with most states, the trade balance is lopsided, strongly in favor of China. This imbalance should be relatively improved by promoting tourism once the COVID-19 pandemic subsides, with Egypt pursuing a first year a target of one million Chinese tourists subject to further expansion. Additionally, both countries also succeeded in achieving positive economic growth during the COVID-19 pandemic, with China growing by $2.3 \%$ and Egypt by $3.5 \%$ in 2020.

It is important to note that China has played an indispensable role in Egypt's development endeavors, particularly in the field of infrastructure and manufacturing. China has been actively involved in several mega-projects, such as the development of a new administrative capital, where CSCEC is constructing the Financial and Business District. Furthermore, the China-Egypt TEDA Suez Economic and Trade Cooperation Zone has been an outstanding success and is the embodiment of the strong bilateral economic cooperation between both countries. Most of the investments in this area are export-oriented and have contributed to Egypt's vision of becoming an export-based manufacturing hub.

Egypt had previously suffered from chronic electricity shortages, but through the wise leadership of President El-Sisi, Egypt has now a significant power surplus, which has paved the way for Egypt to become a cross-regional energy hub. Currently, Egypt is working on expanding its electricity surplus to countries in Africa, West Asia as well as Europe. Furthermore, both Egypt and China have been committed to the promotion of sustainable development in a green and environmentally friendly manner to combat climate change. The Government of Egypt, through the Ministry of Electricity and Renewable Energy, issued its Integrated Sustainable Energy Strategy for the period between 2015 and 2035, in which Egypt is aiming to increase the supply of electricity from renewables from $20 \%$ in 2022 to $42 \%$ in 2035. Many Chinese companies, such China Gezhouba Group (CGGC) and TBEA, are playing an integral role in this endeavor, actively participating in the Benban Solar Energy Park in Aswan province as well as other solar and wind parks being developed across the country to fulfill this ambitious target. Several companies are undergoing discussions to develop industrial complexes to produce solar panels to meet the demand in Egypt and the region.

Such projects and more could not have been undertaken without Egypt's ambitious and successful economic reform program that resulted in achieving very important targets, mainly in macroeconomic stability and market confidence, resulting in continued growth and improved fiscal accounts. Egypt is now focusing on sustaining this stable trajectory and is pursuing sustained and inclusive economic growth. The development of infrastructure in a sustainable and environmentally friendly manner 
ensures closer cooperation with China and is a means to bridge geographic gaps and distances. To achieve these aims, there it is necessary to remain dedicated to developing intercontinental economic integration and spur sustainable economic development, progress and prosperity. For Egypt to achieve its goals, it is essential to create a framework to catalyze the involvement of private sector capital alongside the public sector, allowing it to develop major projects that encourage cross-border connectivity and develop the necessary foundations to create infrastructure and fill the huge infrastructure financing gap across our respective regions. Here China is playing an important role, which will be subject to further diversification and intensity in the future.

Egypt and China have also been in close cooperation in several important multilateral development initiatives such as the visionary Belt and Road Initiative, proposed by H.E. President Xi Jinping. Egypt's support for the initiative stems from its belief in the core mandate in the goal of the Belt and Road Initiative, which aims to enhance cooperation between different continents and is evidence of our nations' desire to spur globalization and connectivity. Here, Egypt, with its strategic location and position as a signatory of multiple Free Trade Agreements with several major economic blocks and regions, is a natural supporter of this important initiative. This represents a real opportunity for Chinese firms to invest and export their product directly to these blocs and regions without any barriers, provided they acquire the required minimum local value content in Egypt. What is of significant importance is the fact that because of its geographic position along the Suez Canal maritime route, a significant cut in transport cost is projected. Thereby offering a tremendous opportunity and advantage to captains of industry in China.

Egypt has also joined in Chinese international initiatives including being a founding member, the first from the African continent, of the Asian Infrastructure Investment Bank, which has gone on to become a world-class multilateral development bank as well as a multilateral cooperation center for development finance.

On the political level, the relationship between Egypt and China has become increasingly stronger. This is based on many facts, including the six visits of President El-Sisi to China during the last seven years and the historic visit of President Xi Jinping to Egypt in 2016. Close consultations among the two presidents were a common phenomenon, and both leaders had an extended conversation on February 22nd of this year. This strong relationship between both leaders in itself has created a solid framework for fostering relations between the two states. Perhaps a further illustration of this strong political tie has been the communication during the COVID19 pandemic. At the outset, during the most difficult time of the pandemic in China, Egypt did not hesitate to send immediate medical assistance to China, and President El-Sisi instructed the Minister of Health to take further medical supplies during his visit to Beijing in March 2020 to show solidarity with the Chinese government and people in their battle against COVID-19. This was the first visit by any foreign official during the most serious period of the pandemic crisis in China. Another very symbolic gesture from the Egyptian president was to project the Chinese flag on some Egyptian monuments in a sign of solidarity between the people of Egypt and China. 
When COVID-19 reached Egypt, China was the first to stand by Egypt. Several very valuable and urgently needed shipments of medical supplies, including ventilators, masks and suits were gifted to Egypt and dispatched immediately. In addition, when they were most scarce, China helped Egypt purchase much needed medical supplies. Most recently, two shipments of three hundred thousand vaccines have already been sent, and further negotiations are underway to purchase more vaccines, which are much needed in Egypt. The COVID-19 pandemic may be a disaster that has affected all of humanity, but it also served as an opportunity for a mutual expression of friendship and solidarity between Egypt and China.

Having undergone a tremendous leap forward, the relationship between the two countries are poised for further development in the years to come. The joint convictions of both leaders point in this direction. This is also strongly complimented by what the two states can offer one another. It is true that one can focus on the historical legacy of their relationship to predict the future, but that would be an incomplete vision. History can but offer a limited vision into the future of their bilateral relations, which must be set within the framework of mutual benefit, common vision and a broad range of complementary aspects, all of which are found in abundance in this bilateral relationship. All practical indicators seem to point to the fact that the lands of the Dragon and the Pharaohs are destined to bend geographic distance through strong convictions and practical benefits-a classic win-win formula.

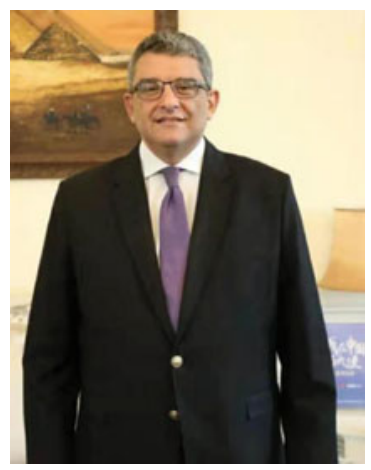

H.E. Mr. Mohamed Abd El-Sattar Elbadri is the Ambassador Extraordinary and Plenipotentiary of the Arab Republic of Egypt to the People's Republic of China and Mongolia. Mr. Elbadri served as Assistant Minister of Foreign Affairs of the Arab Republic of Egypt \& Permanent Representative to the League of Arab States from 2017-2019. He used to work at the Focal Point of Egypt on the issues of culture, peace and dialogue among civilizations and was responsible for Middle Eastern Affairs at the United Nations Security Council and the General Assembly. Mr. Elbadri was born in 1967 and received his $\mathrm{PhD}$ with honors in International Relations and Diplomatic History from Bilkent University, Ankara in 1995 and has published several books. 
Open Access This chapter is licensed under the terms of the Creative Commons AttributionNonCommercial-NoDerivatives 4.0 International License (http://creativecommons.org/licenses/bync-nd/4.0/), which permits any noncommercial use, sharing, distribution and reproduction in any medium or format, as long as you give appropriate credit to the original author(s) and the source, provide a link to the Creative Commons license and indicate if you modified the licensed material. You do not have permission under this license to share adapted material derived from this chapter or parts of it.

The images or other third party material in this chapter are included in the chapter's Creative Commons license, unless indicated otherwise in a credit line to the material. If material is not included in the chapter's Creative Commons license and your intended use is not permitted by statutory regulation or exceeds the permitted use, you will need to obtain permission directly from the copyright holder.

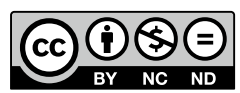

